\title{
Key Factors in the Face Stability Analysis of Shallow Tunnels
}

\author{
${ }^{1}$ Daniel Dias and ${ }^{2}$ Pierpaolo Oreste \\ ${ }^{1}$ University Grenoble Alpes, LTHE, F-38000 Grenoble, France \\ ${ }^{2}$ DIATI, Faculty of Engineering, Politecnico di Torino, Italy
}

Received 2013-06-13, Revised 2013-08-01; Accepted 2013-08-02

\begin{abstract}
Stability of the excavation face in shallow tunnels and in poor ground is at present a relevant problem in tunnelling. A new calculation procedure is illustrated in this study for the analysis of the effect on the face stability in shallow tunnels of the following key factors: pre-support structures, presence of groundwater, free length of the tunnel (length of the unsupported span close to the excavation face). The procedure is based on the Limit Equilibrium Method (LEM) applied to the ground core ahead of the face and it is able to offer also a detailed evaluation of the interaction between each reinforcement element at the face and the surrounding ground. The originality of this procedure is the fact that it is an unified one and permits to take into account all of the following terms: fiberglass longitudinal dowels, non supported tunnel length, pre-support structures and water level ahead of the excavation face. The main result of the calculation concerns the safety factor of the excavation face. Based on a real case (Biella tunnel), a parametric study has been developed to show the influence of the several elements that affect the tunnel face stability in shallow tunnels.
\end{abstract}

Keywords: Tunnel, Tunnel Face, Pre-Reinforcement, Longitudinal Fiberglass Dowel, Pre-Support, Groundwater, Shallow Tunnel, Limit Equilibrium Method, Safety Factor

\section{INTRODUCTION}

The stability of an excavation face of a shallow tunnel depends not only on the characteristics of the ground, on the dimensions of the tunnel and on its depth with respect to the ground surface, but also on the following factors:

- The possible presence of excavation face reinforcements elements

- Possible pre-support works

- The free length (distance of the tunnel supports from the excavation face) (Oreste, 2003; Do et al., 2013)

- The possible presence of groundwater

Face reinforcement elements are usually made up of fibreglass dowels that are inserted into previously bored holes, which have been sealed with the surrounding soil through the injection of cemented mortar. This kind of intervention has proved to be efficacious in increasing the safety factor of the excavation face and it has also resulted flexible and easy to carry out (Dias et al., 1997; 1998; Hallak et al., 1999; Kamata and Mashimo, 2003). These are the reasons behind the widespread use of face bolting with fibreglass dowels in shallow tunnels in poor ground in recent years (Oreste, 2009; 2013).

Other fundamental aspects, which are described hereafter, should also be taken into account in the evaluation of the stability of the excavation face, as they play a vital role.

The pre-support works that are inserted ahead of the excavation face are structures that have the purpose of unloading stresses from the nucleus of soil ahead of the excavation. These works are frequently conducted together with bolting of the excavation face.

The entity of the free length can have an important influence on the degree of stability of the excavation face, as the load produced by the ground above the portion of the free length can weigh on the nucleus of Corresponding Author: Daniel Dias, University Grenoble Alpes, LTHE, F-38000 Grenoble, France 
ground ahead of the excavation face and reduce its degree of stability.

Finally, the presence of water, especially in permeable soil (sands and gravels), can change the effective stress regime in the ground close to the excavation face and can therefore condition its degree of stability. The draining of groundwater may be the most convenient system to increase the safety factor of an excavation face and guarantee its stability, on condition there is no risk of impoverishing the water table in a permanent manner or of producing an inacceptable subsidence on the ground surface.

In this study, after having described the ways of evaluating the degree of stability of an excavation face in natural conditions and in the presence of fibreglass dowels, the influence of the following three key factors on the safety factor of the excavation face is studied: the presence of pre-supports, the entity of the free length and the presence of groundwater. A parametric analysis was developed starting on a well known reference case: the Biella Tunnel in Italy (Oreste, 2009).

\subsection{The Evaluation of the Face Stability Using the Limit Equilibrium Method}

The stability of excavation face in shallow tunnel can be studied using the Limit Equilibrium Method (LEM), dividing the ground ahead of the face into two volumes. These two volumes are considered infinitely rigid and can both present relative displacements between each other with respect to the remaining ground (Fig. 1). For the sake of simplicity, the face section is approximated by a rectangle. The prism ahead of the face-free to slide-can allow the upper parallelepiped (with a triangular base) to move vertically and produce the so-called "rise" effect, which has obvious repercussions on the ground surface.

The main hypothesis on which the LEM is based are:

- The kinematic mechanism of the block occurs by sliding on the lateral surfaces of the two volumes

- It is a static analysis: only the possibility of the initial displacement of the ground blocks is dealt with and the evolution of the potential instability phenomenon is not considered in any way whatsoever

- The potential unstable mass is represented by one or more monoliths that are considered infinitely rigid. Inside theses blocks any break can occur

- The possibility of a progressive break along the sliding surfaces is not considered
It is evident that the LEM is based on particular simplifications of the instability mechanisms and the results should therefore be interpreted carefully. The use of the LEM in the analysis of many instability mechanisms is, however, very common in geotechnical engineering due to its simplicity, to the intuitive nature of the approach and to the possibility of evaluating the degree of stability with safety factors.

In order to evaluate the stability condition of the face, it is necessary to define the strength (limit equilibrium condition) and the active forces on the unstable ground zones so that their ratio can be computed along the possible displacement direction. This implies a set of logical operations:

- Identification of the geometry of possible unstable ground zones, varying the slope angle $\vartheta$

- Evaluation of the geometry (vertexes, volume and areas of the unstable block zones)

- Computation of the volume and surface resultant forces acting on the two unstable blocks

- Evaluation of the resisting forces

- Computation of the safety factor

In the specific case under examination (Fig. 1), block 1 (pyramidal block) is enclosed by the four planes: The excavation face, the two sliding planes, the plane of contact with block 2. Block 2 is instead enclosed by planes: the ground surface, the plane of contact with block 1 , the three vertical planes.

The vertical force $\mathrm{V}$ block 2 applies to block 1 is given by the weight of block 2 , the pressure eventually applied on the surface and the resistance that can be developed on the lateral surfaces of the block when it tries to move downward. $\mathrm{V}$ is obviously only considered if it is positive; if it is negative it is set to 0 , thus block 1 cannot raise block 2 (Fig. 2).

The horizontal force $\mathrm{H}$ block 2 applies to block 1 is produced by the ground shear strength, which can be developed when a horizontal displacement between block 1 and 2 occurs. Also when $\mathrm{H}<0$ it is set to $\mathrm{H}=0$ (Fig. 2).

Once the forces acting on block 1 (its weight $\mathrm{W}_{1}, \mathrm{~V}$, $\mathrm{H}$, the strength on the sliding planes $\mathrm{R}_{\mathrm{a}}$ ) have been determined, it is possible to determine the safety factor as a function of the angle $\vartheta$ Equation 1:

$\mathrm{F}_{\mathrm{s}, \vartheta}=\frac{\mathrm{R}_{\mathrm{a}}+\mathrm{H} \cdot \cos \vartheta}{\left(\mathrm{W}_{1}+\mathrm{V}\right) \cdot \sin \vartheta}$

The forces opposed to the sliding of block 1 appear in the numerator. 


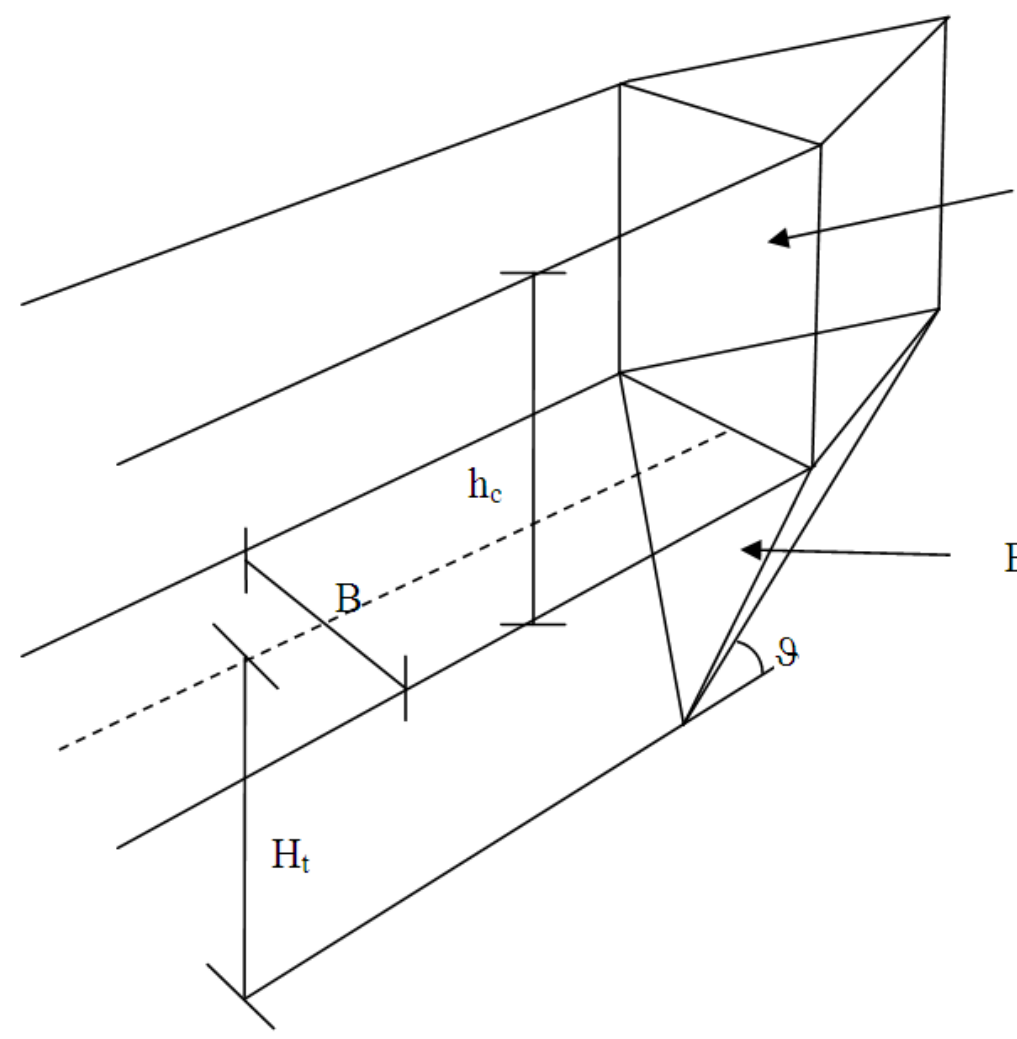

Block 2

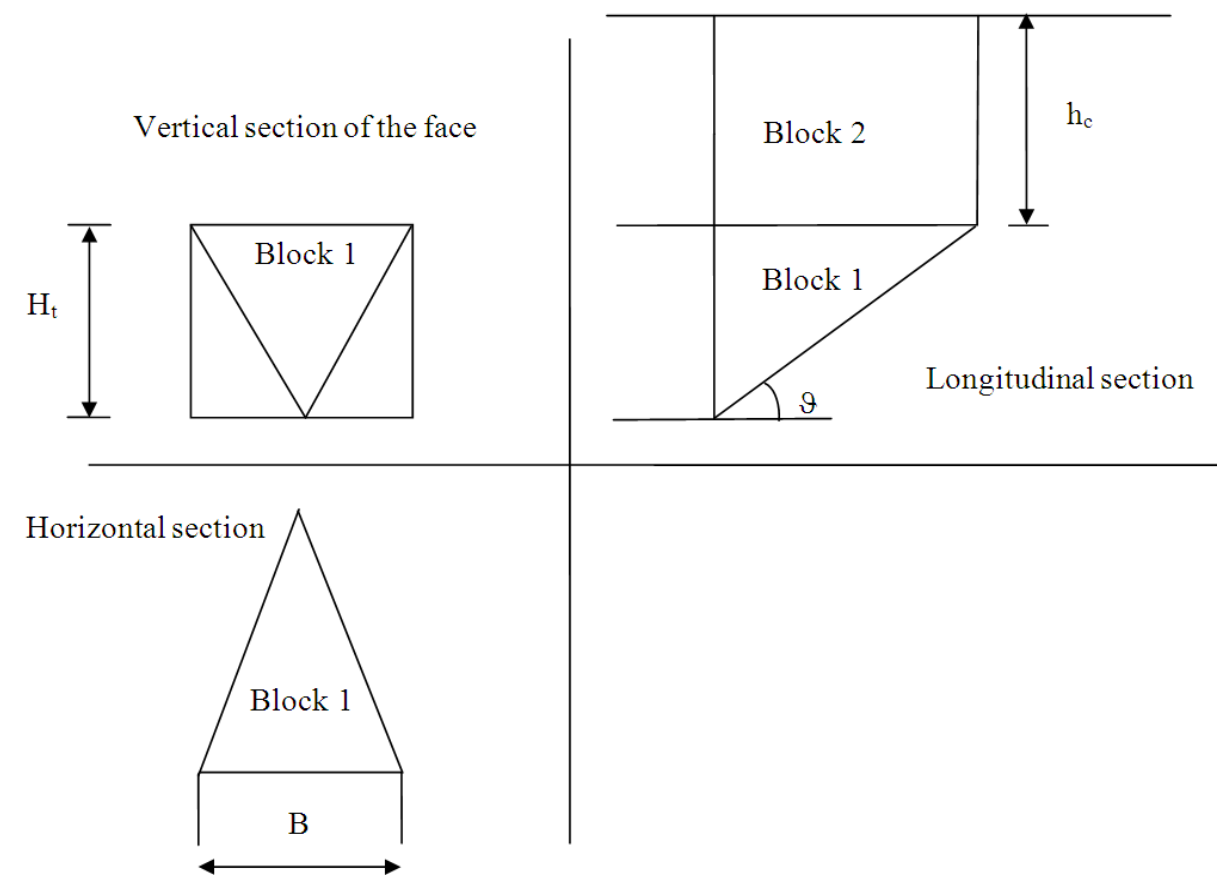

Fig. 1. Tri-dimensional geometry of the blocks considered in the limit equilibrium analysis at the face and orthogonal projections of the two ground blocks (block 1 with pyramidal shape and block 2 with parallelepiped shape and a triangular base) 


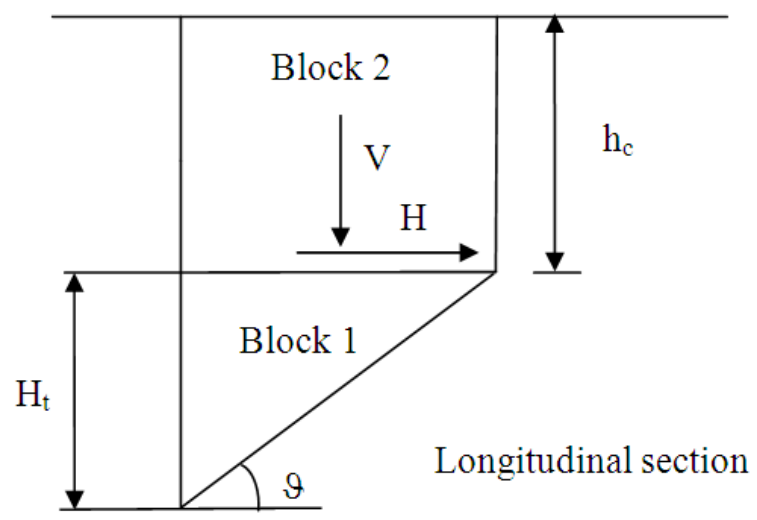

Fig. 2. Forces $\mathrm{V}$ and $\mathrm{H}$ applied by the block 2 to block 1 ahead of the excavation face

That is, the forces mobilized by the ground strength on the sliding planes and the component of $\mathrm{H}$ parallel to the sliding direction. The forces that tend to induce sliding (the components parallel to the sliding direction of the forces $\mathrm{W}_{1}$ and $\mathrm{V}$ ) appear in the denominator.

In more detail (reference is made to half of blocks 1 and 2 for symmetry reasons) Equation 2-5:

$$
\begin{aligned}
& \mathrm{V}=\left(\mathrm{q}+\gamma \cdot \mathrm{h}_{\mathrm{c}}\right) \cdot\left[\frac{\left(\frac{\mathrm{B}}{2} \cdot \mathrm{H}_{\mathrm{t}} \cdot \cot \vartheta\right)}{2}\right]-\mathrm{h}_{\mathrm{c}} \\
& \cdot\left[\left(\frac{\mathrm{B}}{2}\right) \cdot\left(1+\frac{1}{\cos \varepsilon}\right)\right] \cdot\left(\mathrm{c}+\sigma_{\mathrm{n}, \mathrm{m}} \cdot \tan \phi\right) \\
& \mathrm{H}=\mathrm{c} \cdot\left(\frac{\mathrm{B}}{2} \cdot \frac{\mathrm{H}_{\mathrm{t}} \cdot \cot \vartheta}{2}\right)+\mathrm{V} \cdot \tan \phi \\
& \mathrm{R}_{\mathrm{a}}=\mathrm{c} \cdot\left(\frac{\mathrm{B} / 2}{\cos \varepsilon} \cdot \frac{\mathrm{H}_{\mathrm{t}} \cdot \cot \vartheta \cdot \cos \varepsilon}{2 \cdot \cos \chi}\right) \\
& +\left(\mathrm{W}_{1}+\mathrm{V}\right) \cdot \cos \chi \cdot \tan \phi \\
& \varepsilon=\arctan \left(\frac{\mathrm{H}_{\mathrm{t}} \cdot \cot \vartheta}{\mathrm{B} / 2}\right) \\
& \chi=\arctan \left(\frac{\tan \vartheta}{\cos \varepsilon}\right)
\end{aligned}
$$

Where:

$$
\begin{array}{ll}
\mathrm{q} & =\text { The load on the ground surface, } \\
\gamma & =\text { The ground specific weight, } \mathrm{c} \text { and }
\end{array}
$$

$\varphi=$ Respectively the cohesion and the fiction angle of the ground,

$\sigma_{\mathrm{n}, \mathrm{m}}=$ The average stress normal to the vertical surfaces of block 2 .

As the angle $\vartheta$ of the potential sliding surface is a priori not known, the minimum value of the safety factor $F_{\mathrm{s}, \vartheta}$ is assessed by varying $\vartheta$ between 0 and $90^{\circ}$ Equation 6 :

$$
\mathrm{F}_{\mathrm{s}}=\min \left[\mathrm{F}_{\mathrm{s}, 9}\right]_{9=0 \div 90^{\circ}}
$$

It is possible, again through the use of LEM, to take into consideration the presence of fibreglass dowels, adopting the procedure presented in Oreste and Dias (2012). This procedure makes it possible to evaluate the interaction between each dowel and the surrounding ground in the moment in which block 1 shows the tendency to move by sliding along the two lower planes.

This formulation allows obtaining the evaluation of the stress-strain behaviour of a single dowel at the face and a quick dimensioning of the reinforcement system.

The unknown factors are the global forces (axial $\mathrm{N}$, shear $\mathrm{T}$ and bending moment $\mathrm{M}$ ) developed along the dowels and which are functions of a dislocation displacement of the potentially unstable block 1 .

The dowels can be designed through a sequence of tests, assuming different reinforcement schemes, until the safety factor of the potentially unstable block 1 at the excavation face is higher than the minimum allowed value.

The global safety factor $\mathrm{F}_{\mathrm{s}, \vartheta}$, (Equation 1) of unstable block 1 must now be re-evaluated, taking into consideration the stabilising forces produced by each single dowel ( $i=1$ to $n)$ Equation 7:

$$
\mathrm{F}_{\mathrm{s}, \vartheta}=\frac{\mathrm{R}_{\mathrm{a}}+\left(\mathrm{H}+\sum_{\mathrm{i}=1}^{\mathrm{n}} \mathrm{N}_{0, \delta_{\max }, \mathrm{i}}\right) \cdot \cos \vartheta+\left(\sum_{\mathrm{i}=1}^{\mathrm{n}} \mathrm{T}_{0, \delta_{\max }, \mathrm{i}}\right) \cdot \sin \vartheta}{\left(\mathrm{W}_{1}+\mathrm{V}\right) \cdot \sin \vartheta}
$$

where, $R_{a}$ is now given by the following expression Equation 8:

$$
\begin{aligned}
& \mathrm{R}_{\mathrm{a}}=\mathrm{c} \cdot\left(\frac{\mathrm{B} / 2}{\cos \varepsilon} \cdot \frac{\mathrm{H}_{\mathrm{t}} \cdot \cot \vartheta \cdot \cos \varepsilon}{2 \cdot \cos \chi}\right) \\
& +\left[\begin{array}{l}
\left(\mathrm{W}_{1}+\mathrm{V}-\sum_{\mathrm{i}=1}^{\mathrm{n}} \mathrm{T}_{0, \delta_{\max }, \mathrm{i}}\right) \\
\cdot \cos \chi+\left(\sum_{\mathrm{i}=1}^{\mathrm{n}} \mathrm{N}_{0, \delta_{\max }, \mathrm{i}}\right) \cdot \cos \varepsilon \cdot \sin \chi
\end{array}\right] \cdot \tan \phi
\end{aligned}
$$

with $\mathrm{R}_{\mathrm{a}} \geq 0$. 
$\mathrm{N}_{0, \delta_{\max }}$ and $\mathrm{T}_{0, \delta_{\max }}$ are two maximum stabilising actions that can be offered by each dowel to the potentially unstable ground block 1: the axial force $\mathrm{N}_{0}$, $\delta_{\max }$ is directed towards the excavation face and the transversal force $\mathrm{T}_{0, \delta_{\max }}$ is perpendicular to the dowel, directed upwards.

The presence of dowels obviously induces an increase in the face safety factor value in accordance with the characteristics of the chosen reinforcement system.

\subsection{Analytical Formulations for Considering Pre-Support, free Length and Groundwater in the Calculation of the Face Safety Factor}

\subsubsection{Pre-Support Influence}

Consolidation with only fibreglass dowels is often not sufficient to guarantee the stability of an excavation face and it becomes necessary to add a pre-support work ahead of the excavation face. Pre-support is a structure that is installed ahead of the excavation face and which allows the nucleus of ground ahead of the excavation face to be unloaded, from a stress point of view. The effect is that of reducing or completely eliminating the force $\mathrm{V}$ that the ground above (block 2) applies to block 1. In order to be efficacious, the pre-support should have a certain depth beyond the excavation face in order to interpose between block 1 and block 2, even for relatively low values of $\vartheta$.

Pre-support structures can be divided into two main categories: those that have a circumferential continuity on the transversal profile of the tunnel and those that do not have such circumferential continuity.

Two typical pre-support structures with circumferential continuity, which are usually associated with fibreglass dowel reinforcement (Lunardi, 2008), are shown in Fig. 3: the Mechanical Pre-cutting Advance Shell method, which consists in the installation of a concrete lining all around the excavation profile ahead of the face, by first making a cut with a saw and then filling it with concrete; the Advance Shell of improved ground method, which is used to improve the ground, through the use of fibreglass elements fitted with valves that are then injected, makes it possible to create a reinforced arc of ground all around the excavation profile and ahead of the face, which has better mechanical characteristics than the natural ground. These structures should obviously foresee a certain overpositioning in order to guarantee their continuity along the longitudinal axes of the tunnel and should therefore have a slightly divergent direction with respects to the horizontal.
Both of these types of pre-support are usually dimensioned in such a way as to be able to bear and laterally unload force $\mathrm{V}$, produced by block 2 and thus prevent it from acting on block 1 . They are only totally efficacious for angles of $\vartheta$ of the intersection line of the sliding planes of block 1 with respect to the horizontal above a value of $\vartheta_{0}=\arctan \left(H_{t} / L_{p s}\right)$, where $H_{t}$ is the tunnel height and Lps is the length of the pre-support ahead of the excavation face.

The efficacy of such pre-supports is only partial for $\vartheta \leq \vartheta_{0}$.

In the presence of pre-supports with circumferential continuity, the part $\Delta \mathrm{V}$ of force $\mathrm{V}$, which is transferred externally to block 1, is (Fig. 4a; Fig. 4b) Equation 9:

$$
\begin{aligned}
& \Delta \mathrm{V}=\frac{\left(\mathrm{q}+\gamma \cdot \mathrm{h}_{\mathrm{c}}\right)}{2} \cdot \frac{\mathrm{B}}{2} \cdot \\
& {\left[\mathrm{H}_{\mathrm{t}} \cdot \cot \vartheta-\frac{\left(\mathrm{H}_{\mathrm{t}} \cdot \cot \vartheta-\mathrm{L}_{\mathrm{ps}}\right)^{2}}{\mathrm{H}_{\mathrm{t}} \cdot \cot \vartheta}\right]-\mathrm{h}_{\mathrm{c}} \cdot} \\
& {\left[\begin{array}{l}
\left.\frac{\mathrm{B}}{2} \cdot\left(1-\frac{\mathrm{H}_{\mathrm{t}} \cdot \cot \vartheta-\mathrm{L}_{\mathrm{ps}}}{\mathrm{H}_{\mathrm{t}} \cdot \cot \vartheta}\right)\right] \cdot\left(\mathrm{c}+\sigma_{\mathrm{n}, \mathrm{m}} \cdot \tan \phi\right) \\
\cdot\left(1+\frac{1}{\cos \varepsilon}\right)
\end{array}\right]}
\end{aligned}
$$

If $\left(\mathrm{H}_{\mathrm{t}} \cdot \cot \vartheta-\mathrm{L}_{\mathrm{ps}}\right)<0$ we have to put $\left(\mathrm{H}_{\mathrm{t}} \cdot \cot \vartheta-\mathrm{L}_{\mathrm{ps}}\right)=0$

The steel pipe umbrella system in advancement is instead a pre-support structure that does not have circumferential continuity (Fig. 5). These structures operate in the longitudinal direction and produce a stress unloading of the nucleus of ground ahead of the face, transferring force $\mathrm{V}$ to the last steel set close to the excavation face and to the portion of stable ground, located beyond block 1 (Fig. 6a; Fig. 6b). Each pipe (composed of tubular steel elements with an external diameter of $\Phi_{\text {ext }}$ and thickness s) has a length 1 of crossing block 1 , in function of the position in the horizontal section: this length is greater in the central pipes and shorter in the peripheral ones. The value of 1 can be expressed in function of the distance $\mathrm{x}$ from the central axis of the tunnel Equation 10:

$$
1=H_{t} \cdot \cot \vartheta \cdot \frac{B / 2-x}{B / 2}
$$

The pipes that have a residual length Lps below 1 are not active. The same pipe can obviously be inactive for small values of $\vartheta$ and active for higher values of $\vartheta$. 

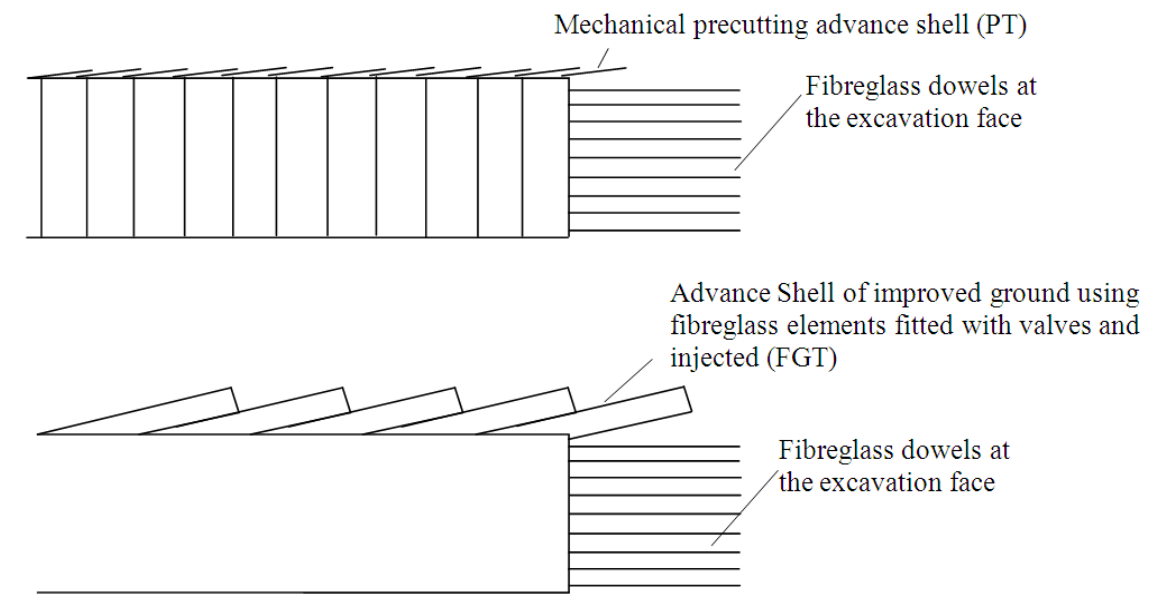

Fig. 3. Pre-support structures with circumferential continuity associated with fibreglass dowels at the excavation face (Lunardi, 2008): Mechanical pre-cutting advance shell (PT), Advance Shell of improved ground using fibreglass elements fitted with valves and injected (FGT)

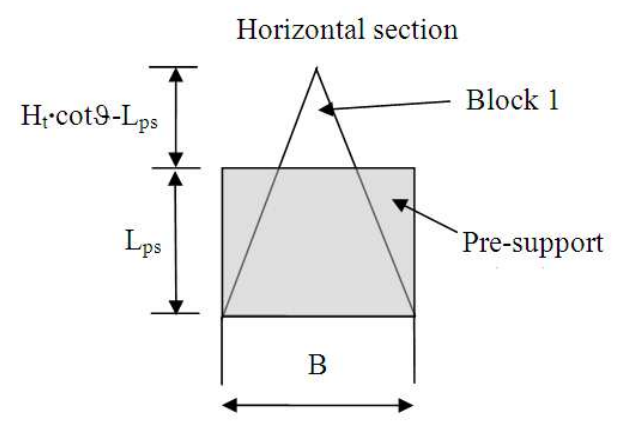

(a)

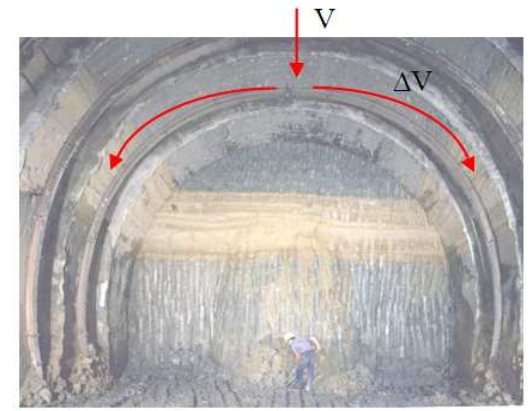

(b)

Fig. 4. Pre-support structure with circumferential continuity along the perimeter of the transversal section of the tunnel. (a) Schematic geometry of the horizontal section (seen from above); (b) View of the pre-support structure with indications of the lateral transfer mechanism of force $\mathrm{V}$ redrawn from (Lunardi, 2008)

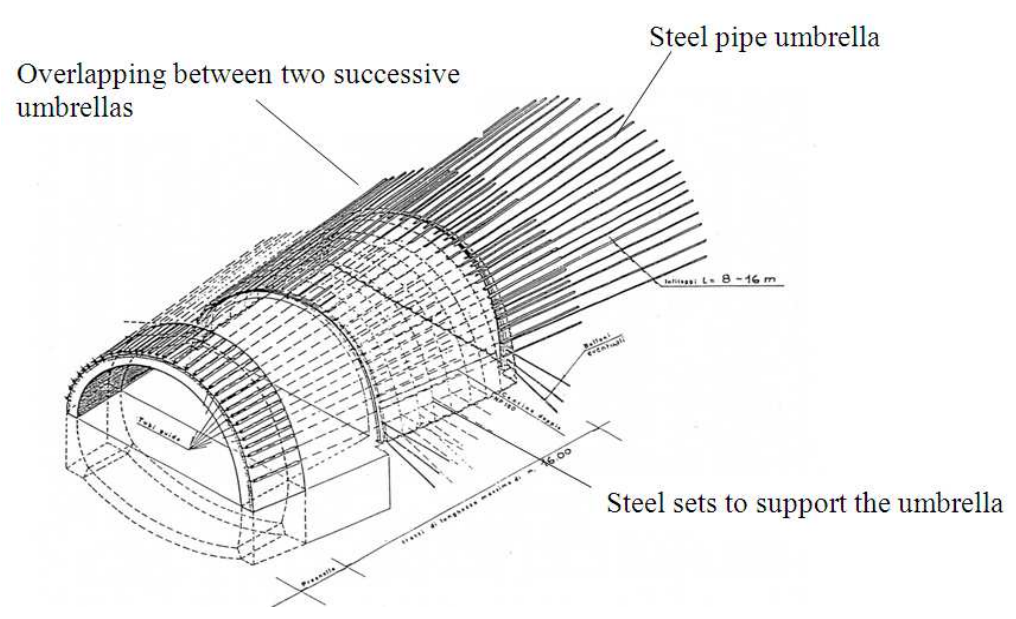

Fig. 5. Pre-support structure using steel pipe umbrella from (Benedetto et al., 1991) 
Longitudinal section

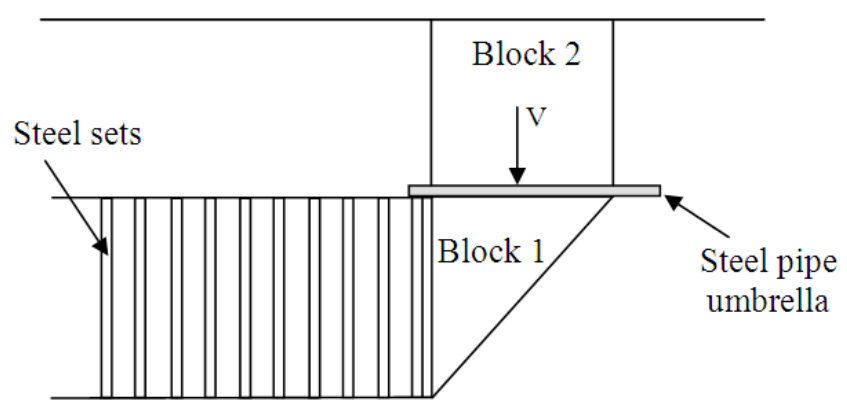

(a)
Horizontal section

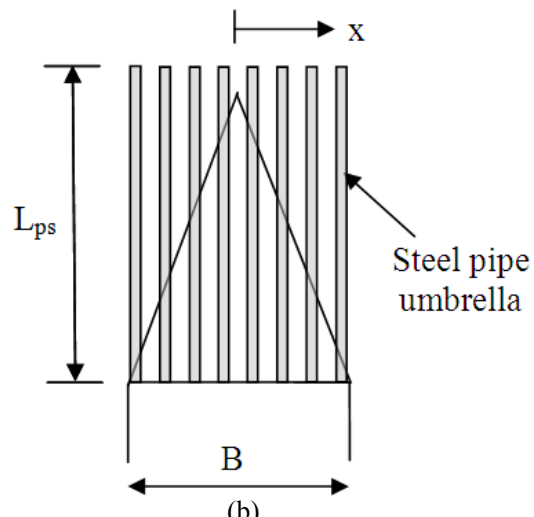

(b)

Fig. 6. Protection mechanism of the ground nucleus ahead of the face (block 1) through a steel pipe umbrella in advancement (presupport structure without circumferential continuity)

If we hypothesise the pipes fixed at the two edges (in correspondence to the last steel set and in the portion of stable ground), the maximum linear load $p_{\max }$ that the individual pipe can bear is Equation 11:

$$
\mathrm{p}_{\max }=\frac{24 \cdot \mathrm{J} \cdot \sigma_{\mathrm{y}}}{\varphi_{\mathrm{ext}} \cdot 1^{2}}
$$

Where:

$\sigma_{\mathrm{y}}=$ The yielding stress of the steel

$\mathrm{J}=$ The moment of inertia of the transversal section of the tubular element used as a pipe

As 1 increases, the maximum linear load that the individual pipe can bear diminishes.

If we hypothesise that force $\mathrm{V}$ is applied from block 2 through a homogeneous pressure on the contact surface between the two blocks, a linear load $\mathrm{p}$ is obtained that is equal to Equation 12:

$$
\mathrm{p}=\frac{2 \cdot \mathrm{V} \cdot \mathrm{i}}{\frac{\mathrm{B}}{2} \cdot \mathrm{H}_{\mathrm{t}} \cdot \cot \vartheta}
$$

where, $i$ is the inter-axis between the pipes.

When $p$ is below or equal to $p_{\max }$, the pipe is able to transfer all the force that it is subjected to outside block 1 . When $\mathrm{p}$ is above $\mathrm{p}_{\max }$, the pipe shows plastic hinges at the edges and should therefore be considered ineffective.

In the presence of a pipe umbrella, the part of $\Delta \mathrm{V}$ of force $\mathrm{V}$, which is transferred outside block 1 , should be as follows Equation 13:

$$
\Delta \mathrm{V}=\sum_{\mathrm{j}=1}^{\mathrm{n}}(\overline{\mathrm{p}} \cdot 1)
$$

Where:

$\mathrm{n}=$ The number of pipes that affect the half section of the tunnel $(\mathrm{n}=\mathrm{E}(\mathrm{B} /(2 \cdot \mathrm{i}))+1)$

$1=$ The crossing length of block 1

$$
\begin{aligned}
& \overline{\mathrm{p}}=\mathrm{p} \text { if } \mathrm{p} \leq \mathrm{p}_{\max }, \overline{\mathrm{p}}=0 \text { if } \mathrm{p}>\mathrm{p}_{\max } \\
& \mathrm{p}_{\max }=\frac{24 \cdot \mathrm{J} \cdot \sigma_{\mathrm{y}}}{\varphi_{\text {ext }} \cdot 1^{2}} \text { if } 1 \leq \mathrm{L}_{\mathrm{ps}}, \mathrm{p}_{\max }=0 \text { if } \mathrm{l}>\mathrm{L}_{\mathrm{ps}} .
\end{aligned}
$$

The jet-grouting column umbrella behaves like the first type of structure (with circumferential continuity), if the columns are installed near each other along the tunnel profile (Fig. 7). If the columns are not close together, they behave like the second type of structure (without circumferential continuity). In the latter case, the same Equation, 10-13, that were developed for the steel pile umbrella, should be used, but it is necessary to substitute $\sigma_{\mathrm{y}}$ with the traction strength $\sigma_{\mathrm{t}}$ of the material than constitutes the jet-grouting column in Equation 11 and also the moment of inertia of the tubular steel section with the moment of inertia of the circular section of the jet-grouting column.

Once the value of force $\Delta \mathrm{V}$ that the pre-support structure is able to transfer outside block 1 has been identified, it is possible to calculate the safety factor of the excavation face with the same Equation, 1-8, substituting $\mathrm{V}$ with the term $(\mathrm{V}-\Delta \mathrm{V})$ for each value of $\vartheta$ considered. 


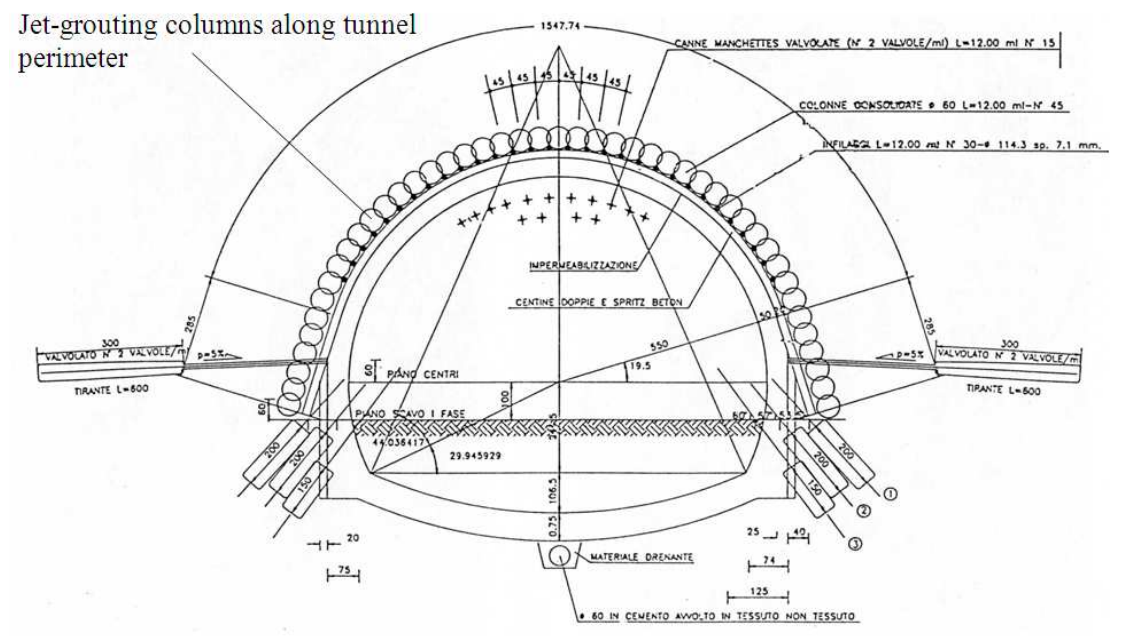

Fig. 7. Pre-support structure using jet-grouting column umbrella (columns installed near each other along the tunnel profile) from (Benedetto et al., 1991)

Longitudinal section

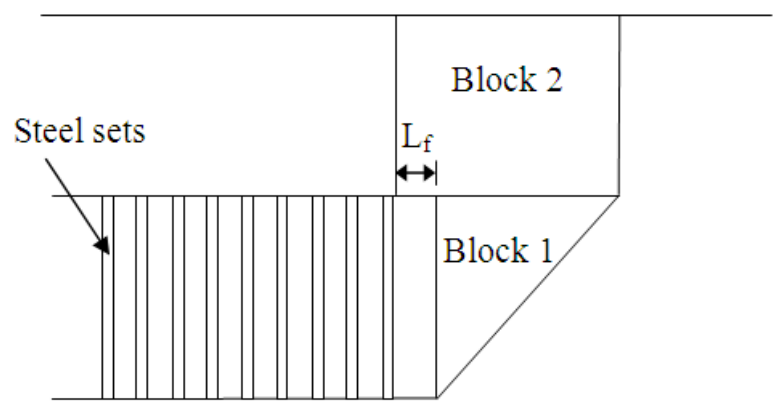

(a)
Horizontal section

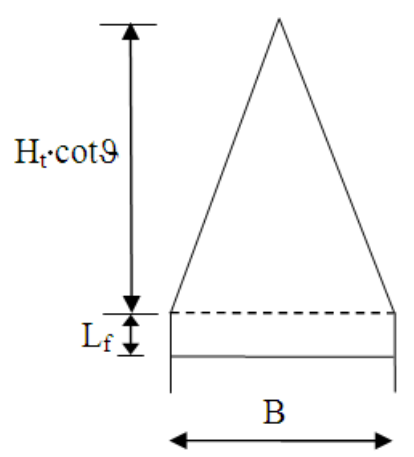

(b)

Fig. 8. Definition of the free length $\left(\mathrm{L}_{\mathrm{f}}\right)$ in a longitudinal tunnel section (a) and in a horizontal section seen from above (b)

\subsection{Free Length Influence}

The free length $\mathrm{L}_{\mathrm{f}}$ in a tunnel is the distance between the excavation face and the edge of the installed supports and it defines the dimensions of the section of tunnel, close to the excavation face, that has not yet been subjected to support works. It is usually just slightly more than the front excavation step subsequent to the excavation operations.

Such a free length can influence the stability of the excavation face as it changes the dimensions of block 2 (Fig. 8) and therefore also the entity of force $V$ that block 2 applies to block 1 .
Equation 2 is therefore modified as follows, in order to take into consideration the free length $\mathrm{L}_{\mathrm{f}}$ Equation 14:

$$
\begin{aligned}
& \mathrm{V}=\left(\mathrm{q}+\gamma \cdot \mathrm{h}_{\mathrm{c}}\right) \cdot\left[\frac{\left(\frac{\mathrm{B}}{2} \cdot \mathrm{H}_{\mathrm{t}} \cdot \cot \vartheta\right)}{2}+\frac{\mathrm{B}}{2} \cdot \mathrm{L}_{\mathrm{f}}\right]-\mathrm{h}_{\mathrm{c}} \\
& \cdot\left[\left(\frac{\mathrm{B}}{2}\right) \cdot\left(1+\frac{1}{\cos \varepsilon}\right)+\mathrm{L}_{\mathrm{f}}\right] \cdot\left(\mathrm{c}+\sigma_{\mathrm{n}, \mathrm{m}} \cdot \tan \phi\right)
\end{aligned}
$$

The force $\Delta \mathrm{V}$ which the pre-supports with circumferential continuity unload outside block 1 , in the presence of the free length, now has the value Equation 15: 


$$
\begin{aligned}
& \Delta \mathrm{V}=\frac{\left(\mathrm{q}+\gamma \cdot \mathrm{h}_{\mathrm{c}}\right)}{2} \cdot \frac{\mathrm{B}}{2} \cdot \\
& {\left[\mathrm{H}_{\mathrm{t}} \cdot \cot \vartheta-\frac{\left(\mathrm{H}_{\mathrm{t}} \cdot \cot \vartheta-\mathrm{L}_{\mathrm{ps}}\right)^{2}}{\mathrm{H}_{\mathrm{t}} \cdot \cot \vartheta}+\mathrm{L}_{\mathrm{f}}\right]-} \\
& \mathrm{h}_{\mathrm{c}} \cdot\left[\frac{\mathrm{B}}{2} \cdot\left(1-\frac{\mathrm{H}_{\mathrm{t}} \cdot \cot \vartheta-\mathrm{L}_{\mathrm{ps}}}{\mathrm{H}_{\mathrm{t}} \cdot \cot \vartheta}\right)\right] \cdot\left(\mathrm{c}+\sigma_{\mathrm{n}, \mathrm{m}} \cdot \tan \phi\right)
\end{aligned}
$$

In the case of steel pipe umbrellas or jet-grouting column umbrellas with columns not close to each other (pre-support without circumferential continuity), Equation 11-13 are changed in the following way in order to take into account the free length Equation 16 to 18:

$$
\begin{aligned}
& \mathrm{p}_{\max }=\frac{24 \cdot \mathrm{J} \cdot \sigma_{\mathrm{y}}}{\varphi_{\mathrm{ext}} \cdot\left(1+\mathrm{L}_{\mathrm{f}}\right)^{2}} \\
& \mathrm{p}=\frac{2 \cdot \mathrm{V} \cdot \mathrm{i}}{\frac{\mathrm{B}}{2} \cdot \mathrm{H}_{\mathrm{t}} \cdot \cot \vartheta+\mathrm{B} \cdot \mathrm{L}_{\mathrm{f}}} \\
& \Delta \mathrm{V}=\sum_{\mathrm{j}=1}^{\mathrm{n}}\left[\overline{\mathrm{p}} \cdot\left(1+\mathrm{L}_{\mathrm{f}}\right)\right]
\end{aligned}
$$

dove: $\quad \overline{\mathrm{p}}=\mathrm{p}$ if $\mathrm{p} \leq \mathrm{p}_{\max }, \overline{\mathrm{p}}=0$ if $\mathrm{p}>\mathrm{p}_{\max }$;

$$
\mathrm{p}_{\max }=\frac{24 \cdot \mathrm{J} \cdot \sigma_{\mathrm{y}}}{\varphi_{\mathrm{ext}} \cdot\left(1+\mathrm{L}_{\mathrm{f}}\right)^{2}} \text { if } 1 \leq \mathrm{L}_{\mathrm{ps}}, \mathrm{p}_{\max }=0 \text { if } \mathrm{l}>\mathrm{L}_{\mathrm{ps}} \text {. }
$$

\subsection{Groundwater Influence}

Groundwater influences the effective stress regimes in the ground and therefore also the static condition of the ground portion ahead of the excavation face. It is in particular important to evaluate the trend of the groundwater pressure in correspondence to the sliding surfaces of block 1 , to the contact surface between block 1 and block 2 and to the lateral vertical surfaces of block 2 .

In order to simplify the procedure, it is possible to hypothesise a negative exponential type of trend of the water table (Fig. 9) close to the excavation face. The height of the water table at infinity coincides with the original position, before the perturbation produced by the presence of the excavation is felt.

The height of the water table, with respects to the foot of the tunnel, in function of the distance from the excavation face $y$, can be expressed by the following Equation 19:

$$
\mathrm{h}_{\mathrm{w}}=\left(\mathrm{h}_{\mathrm{c}}+\mathrm{H}_{\mathrm{t}}-\mathrm{z}_{\mathrm{w}, 0}\right) \cdot\left(1-\mathrm{e}^{\left.\ln \left(\frac{1}{2}\right) \cdot \frac{\mathrm{y}}{\overline{\mathrm{y}}}\right)}\right.
$$

where, $\bar{y}$ is the distance from the excavation face at which the water table shows a height $h_{w}$ equal to half what it shows at an infinite distance; $z_{\mathrm{w}, 0}$ is the depth of the water table from the ground surface in its original conditions.

By integrating the pressure of the water $u$ on the sliding surfaces, on the contact surface between block 1 and block 2 and on the lateral vertical surfaces of block 2 , the following three hydraulic forces are obtained.

Hydraulic under-thrust force on the sliding surfaces:

$$
\mathrm{U}_{\mathrm{ss}}=\frac{1}{2} \cdot \int_{\mathrm{Ass}}\left(\gamma_{\mathrm{w}} \cdot \Delta \mathrm{h}_{\mathrm{w}}\right) \cdot \mathrm{dA}
$$

Hydraulic under-thrust force on the contact surface between block 1 and block 2 :

$$
\mathrm{U}_{12}=\frac{1}{2} \cdot \int_{\mathrm{A} 12}\left(\gamma_{\mathrm{w}} \cdot \Delta \mathrm{h}_{\mathrm{w}}\right) \cdot \mathrm{dA}
$$

Hydraulic force on the lateral vertical surfaces of block 2:

$$
\mathrm{U}_{\mathrm{Is} 2}=\frac{1}{2} \cdot \int_{\mathrm{Als} 2}\left(\gamma_{\mathrm{w}} \cdot \Delta \mathrm{h}_{\mathrm{w}}\right) \cdot \mathrm{dA}
$$

where, $A_{s s} A_{12}$ and $A_{1 s 2}$ are the areas of the sliding surfaces, of the contact surface between block 1 and block 2 and of the lateral surfaces of block 2, respectively.

These hydraulic forces modify Equation 2-4 as follows Equation 20 to 22:

$$
\begin{aligned}
& \mathrm{V}=\left(\mathrm{q}+\gamma \cdot \mathrm{h}_{\mathrm{c}}\right) \cdot\left[\frac{\left(\frac{\mathrm{B}}{2} \cdot \mathrm{H}_{\mathrm{t}} \cdot \cot \vartheta\right)}{2}\right]- \\
& \mathrm{h}_{\mathrm{c}} \cdot\left[\left(\frac{\mathrm{B}}{2}\right) \cdot\left(1+\frac{1}{\cos \varepsilon}\right)\right] \cdot \\
& \left(\mathrm{c}+\sigma_{\mathrm{n}, \mathrm{m}} \cdot \tan \phi\right)+\mathrm{U}_{\mathrm{ls} 2} \cdot \tan \phi \\
& \mathrm{H}=\mathrm{c} \cdot\left(\frac{\mathrm{B}}{2} \cdot \frac{\mathrm{H}_{\mathrm{t}} \cdot \cot \vartheta}{2}\right)+\left(\mathrm{V}-\mathrm{U}_{12}\right) \cdot \tan \phi
\end{aligned}
$$




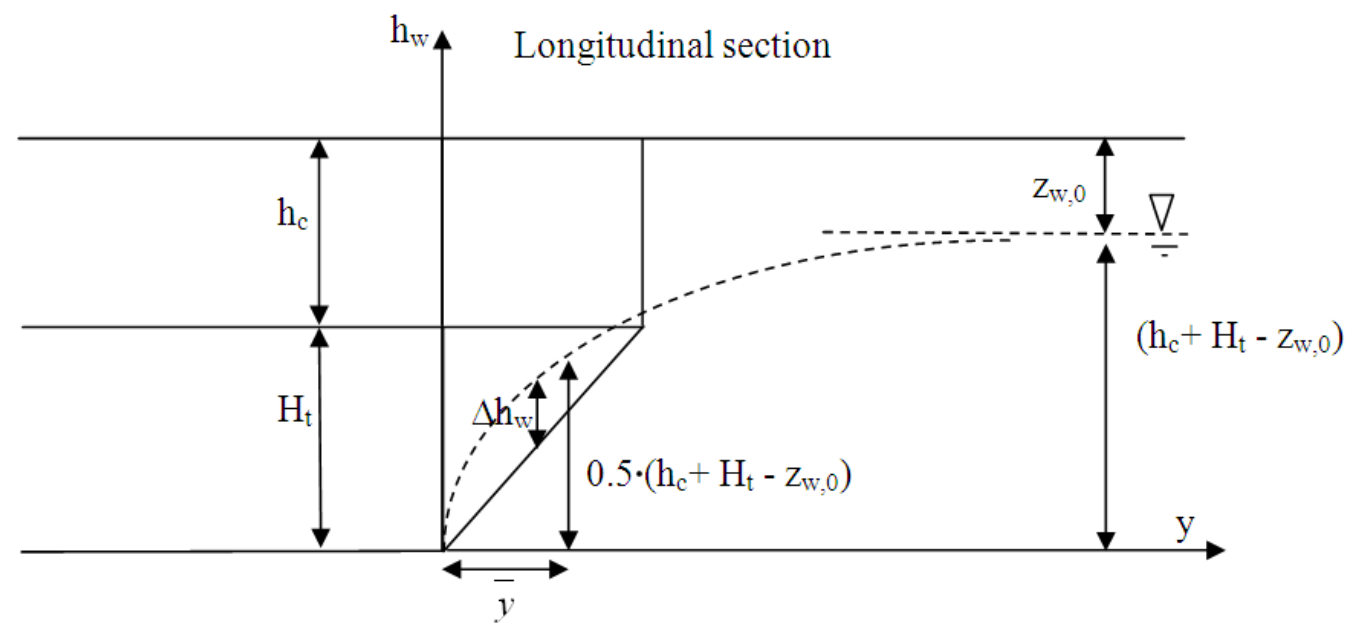

Fig. 9. Qualitative trend of the position of the water table in function of the distance from the excavation face. Key: $\Delta \mathrm{h}_{\mathrm{w}}:$ height of the water table with respect to the sliding surfaces

$\mathrm{R}_{\mathrm{a}}=\mathrm{c} \cdot\left(\frac{\mathrm{B} / 2}{\cos \varepsilon} \cdot \frac{\mathrm{H}_{\mathrm{t}} \cdot \cot \vartheta \cdot \cos \varepsilon}{2 \cdot \cos \chi}\right)$

$+\left[\left(\mathrm{W}_{1}+\mathrm{V}\right) \cdot \cos \chi-\mathrm{U}_{\mathrm{ss}}\right] \cdot \tan \phi$

Equation 8-15 are modified with the same criteria.

The presence of groundwater can lead to an increase in force $\mathrm{V}$, to a reduction of forces $H$ and $\mathrm{R}_{\mathrm{a}}$ and therefore to a reduction in the safety factor of the excavation face.

An important role is played by the trend of the piezometric height of the water table close to the excavation face. This trend depends on the distances $\bar{y}$ e $\mathrm{z}_{\mathrm{w}, 0}$. For the same original depth of the water table from the ground surface $\left(\mathrm{z}_{\mathrm{w}, 0}\right)$, more permeable grounds show a greater perturbation of the water table (elevated $\bar{y}$ ), while soils with limited permeability show a perturbation of the water table that is limited to the portion of ground close to the excavation face (small $\bar{y}$ ).

\subsection{Reference Studied Case: The Biella Tunnel}

The Biella Tunnel is part of a road connection under construction in the Province of Biella (Italy); it has a polycentric shaped section with an areas of about $104 \mathrm{~m}^{2}$ (Oreste, 2009). Loose sand formations (arkose sands) derived from the decay of the rocky granite substratum, were being crossed by the tunnel. The geomechanical parameters of the ground are reported in Table 1.

The reinforcement scheme at the excavation face in both cases foresaw the use of 40 injected fibreglass pipes (external diameter $\Phi_{\text {ext }} 60 \mathrm{~mm}$, internal diameter $\Phi_{\text {int }} 40$ $\mathrm{mm})$ for a total length of $14 \mathrm{~m}$. The hole diameter $\left(\Phi_{\text {hole }}\right)$ was $150 \mathrm{~mm}$ (Table 2).

Drainage of the excavation face, in the case of the presence of water, was also foreseen. The tunnels were excavated in a single stage with the full tunnel diameter exposed.

The maximum overburden was of about $30 \mathrm{~m}$. Sliding of the face (face collapse) occurred when the residual length of the dowels at the face was $12 \mathrm{~m}$ and the overburden about $10 \mathrm{~m}$ (Table 3). The phenomenon originated at the right sidewall and evolved until it caused an extrusion of the face of more than $3 \mathrm{~m}$. When the failure occurred, water under pressure was present ahead of the face.

From a study of the collapse, it was possible to attribute the cause of the instability to the poor efficiency of the drainage system. The water table had therefore not been completely lowered in the vicinity of the excavation face.

The Biella tunnel presented in this paragraph was studied using the proposed LEM method. For the reference case, the water table was not considered and the lining was set up at the tunnel face. Only the tunnel face reinforcement by longitudinal bolting was considered.

The Fig. 10 show the influence of the longitudinal bolting on the face safety. On the case of Biella, without tunnel face reinforcement, the underground work is unstable. It is necessary to set 40 bolts (length $=10 \mathrm{~m}$ ) at the tunnel face to ensure a safety factor equal to the unity. This remark is in good agreement with the observed collapse. The bolts length seems to have a slight influence if the length is superior to $15 \mathrm{~m}$. 


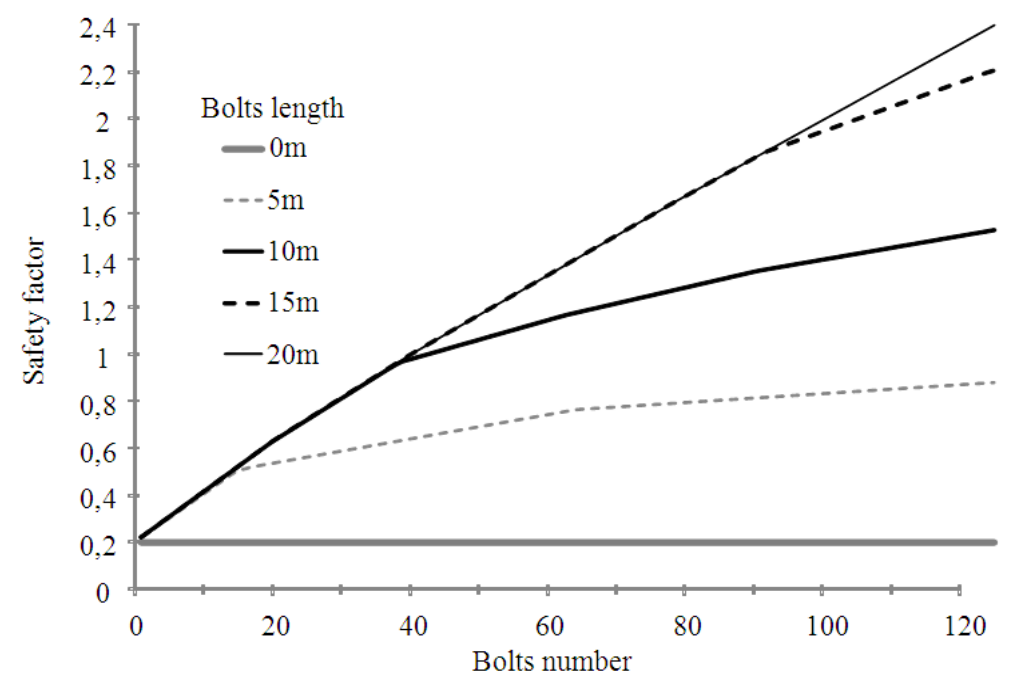

Fig. 10. Influence of the bolts on the safety factor for the reference case

Table 1. Physical and mechanical characteristics of the ground (arkose sands)

\begin{tabular}{lr}
\hline Cohesion c $(\mathrm{MPa})$ & 0.0 \\
Friction angle $\varphi\left({ }^{\circ}\right)$ & 39.0 \\
Specific weight $\gamma\left(\mathrm{kN} / \mathrm{m}^{3}\right)$ & 20.0 \\
Horizontal stress factor $\mathrm{k}_{0}(-)$ & 0.6 \\
\hline
\end{tabular}

Table 2. Mechanical and geometrical characteristics of the fibreglass dowels for the two studied cases

\begin{tabular}{lr}
\hline Hole diameter $\phi_{\text {hole }}(\mathrm{mm})$ & 150.00 \\
External diameter of the & 60.00 \\
$\begin{array}{l}\text { Fibreglass element } \phi_{\text {ext }}(\mathrm{mm}) \\
\text { internal diameter of the }\end{array}$ & 40.00 \\
Fibreglass element $\phi_{\text {int }}(\mathrm{mm})$ & 400.00 \\
Fibreglass yielding stress $\sigma_{\mathrm{y}}(\mathrm{MPa})$ & 0.28 \\
Limit shear stress on the & \\
hole lateral surface $\tau_{\text {lim }}(\mathrm{MPa})$ & 40000.00 \\
Fibreglass elastic modulus $\mathrm{E}_{\mathrm{fg}}(\mathrm{MPa})$ & 20000.00 \\
\hline
\end{tabular}

Table 3. Input parameters for the face safety factor calculation in the two studied cases

\begin{tabular}{lr}
\hline Width of the tunnel $\mathrm{B}(\mathrm{m})$ & 12.0 \\
Height of the tunnel $\mathrm{H}_{\mathrm{t}}(\mathrm{m})$ & 8.7 \\
Overburden on the crown $\mathrm{h}_{\mathrm{c}}(\mathrm{m})$ & 10.0 \\
Depth of the water table $\mathrm{z}_{\mathrm{w}, 0}(\mathrm{~m})$ & 5.0 \\
Load on the surface $\mathrm{q}(\mathrm{MPa})$ & 0.0 \\
\hline
\end{tabular}

Considering this case as a reference for the following study, parametric studies of the influence of the free length (unspanned), the umbrella pipes and the water level are presented. The longitudinal length bolts is assumed to be equal to 20 meters in the following study.

\subsection{Parametric Studies}

\subsubsection{Influence of the Free Length}

Figure 11 show the influence of the free length. The influence of this parameter is not significant if it is not higher than two meters. For lengths superior to 4 meters, the safety factor dramatically decreases. For values of free length inferior to $\mathrm{B} / 3$, this parameter can be neglected when dealing about face stability.

Generally the free length is inferior to $2 \mathrm{~m}$. For tunnels with little-medium surface area $\left(<140 \mathrm{~m}^{2}\right)$ we can therefore consider not important the effect of the free length on the safety factor of the shallow tunnel face.

\subsection{Influence of the Water Table Level}

It is well known that the presence of water at the tunnel face induces a decrease of the safety factor. Figure 12 shows the influence of the water level on the reference case. We can note that the hydraulic influence is important. A bolting density of approximatively $1 \mathrm{bolt} / \mathrm{m}^{2}$ is needed to obtain the stability of the tunnel for $\bar{y}=2 \mathrm{~m}$. Taking into account the water table the safety factor decreases in all the cases:

- $95 \%$ for 0 bolts

- $53 \%$ for 50 bolts

- $46 \%$ for 100 bolts

- $49 \%$ for 125 bolts

For calculations where the face is not reinforced by bolting, the safety factor can drop to 0 suddenly in presence of important rainfall for shallow tunnels in permeable soils (sands and gravels). 
Daniel Dias and Pierpaolo Oreste / American Journal of Applied Sciences 10 (9): 1025-1038, 2013

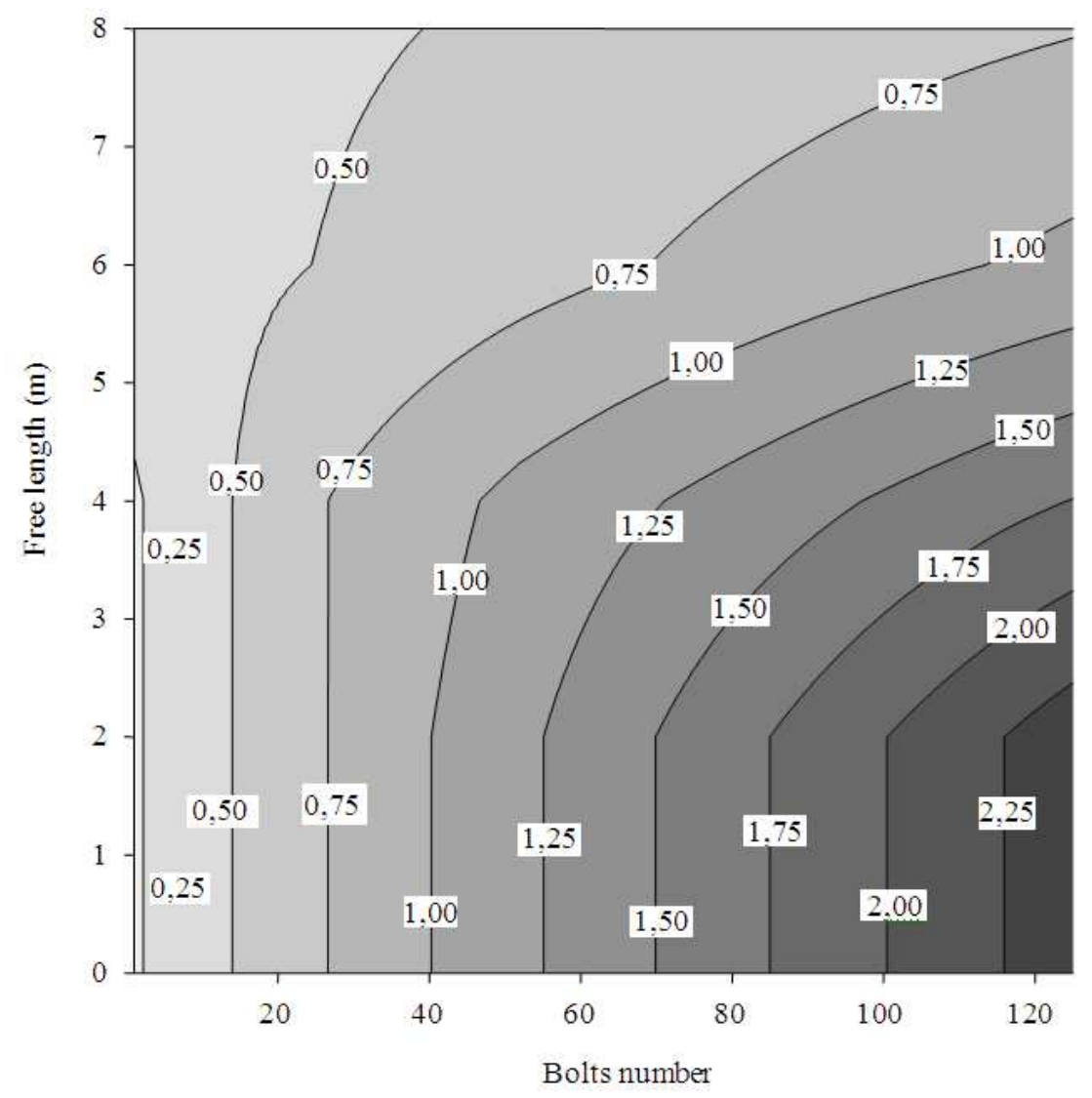

Fig. 11. Influence of bolts and free length on the safety factor

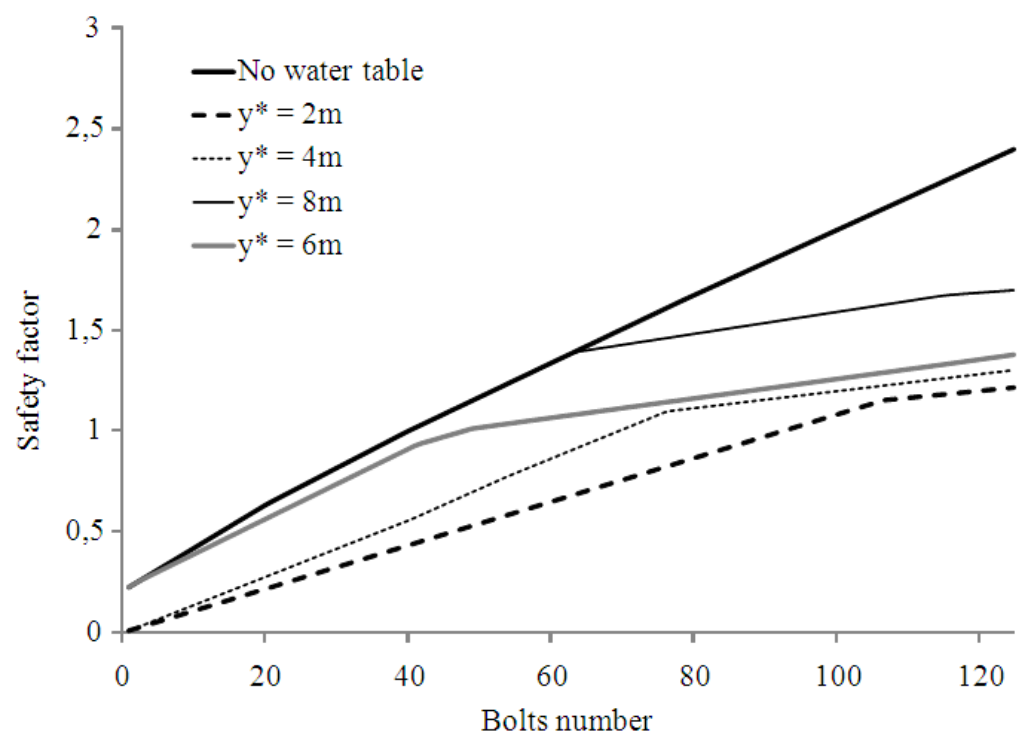

Fig. 12. Influence on the safety factor 
Daniel Dias and Pierpaolo Oreste / American Journal of Applied Sciences 10 (9): 1025-1038, 2013

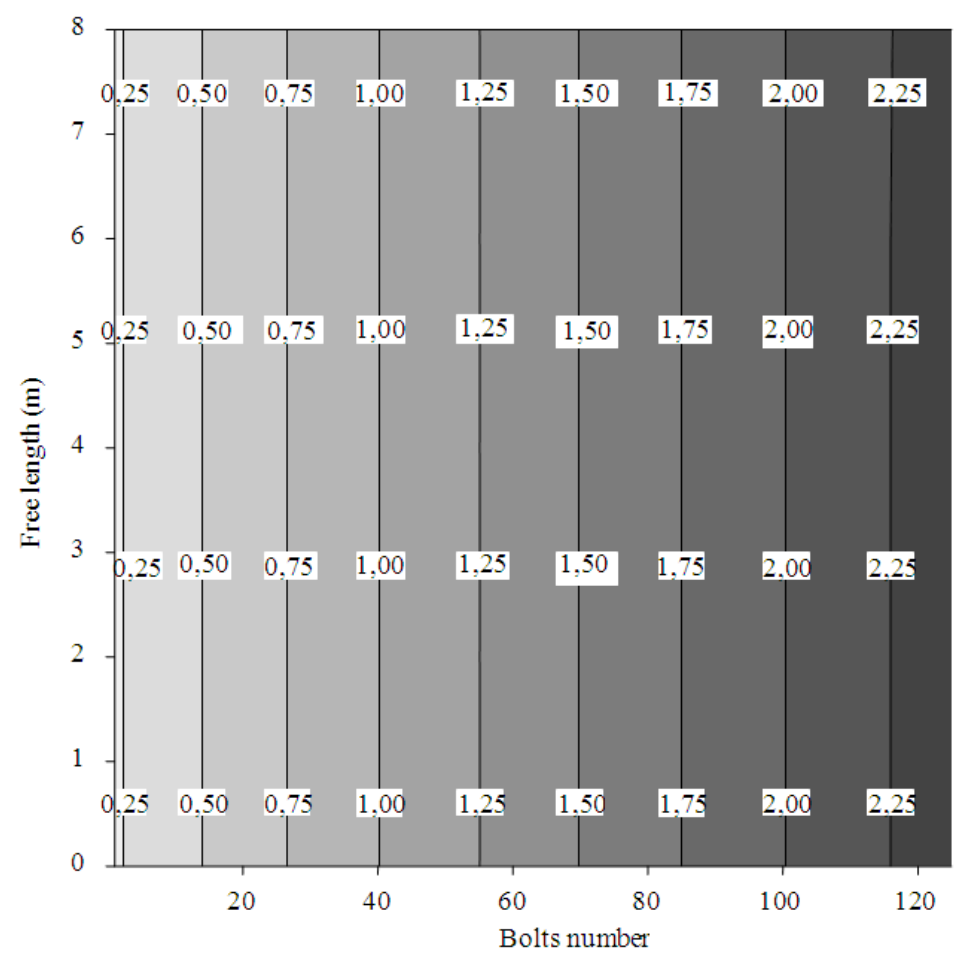

Fig. 13. Umbrella influence on the safety factor

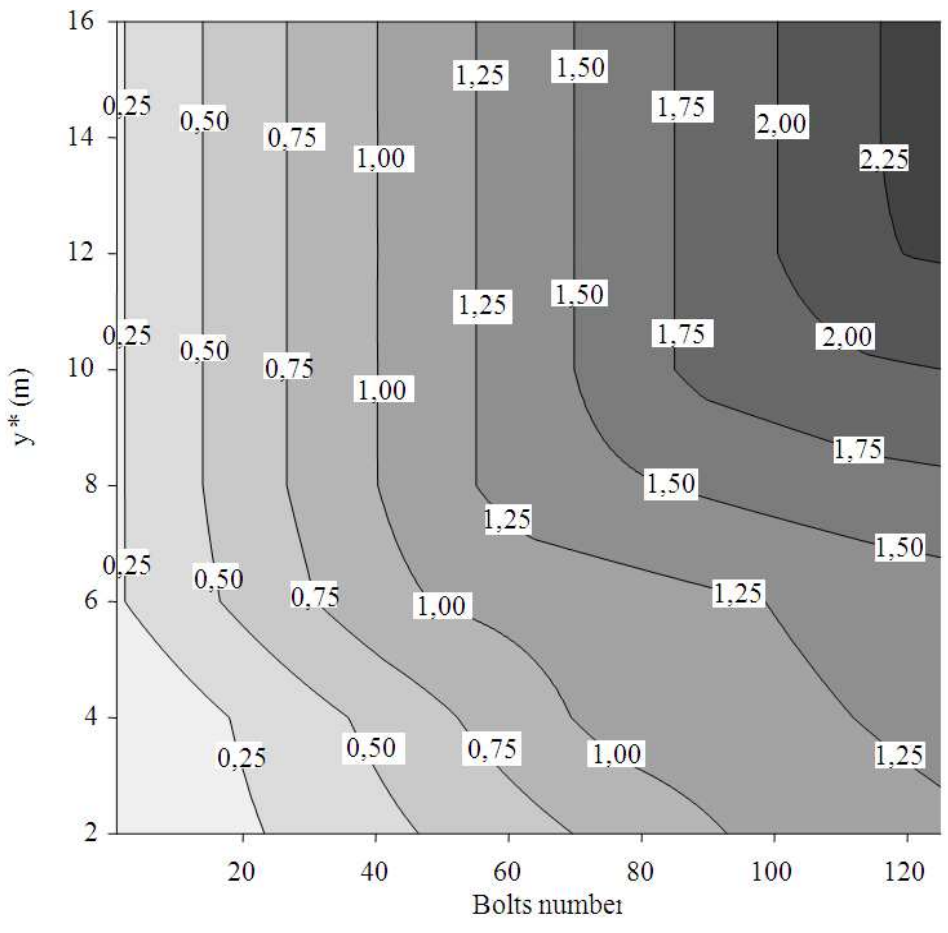

Fig. 14. Influence of water and umbrella on the safety factor 


\subsection{Influence of a Pre-Support Without Circumferential Continuity (Pipe Umbrella Pre-Support System)}

The major interest to use an umbrella is the fact that it permits to keep the safety factor at the same level for high unspanned lengths (Fig. 13). This remark is valid if the umbrella length is higher than the unspanned length.

Pipe umbrella can reduce the effect of the free length for larger sections.

\subsection{Combined Influence of the Presence of Water and of a Pipe Umbrella Support System}

In the case of the support at the tunnel face and the presence of a water table, same results as without umbrella are obtained (Fig. 14). The water influence is higher than the umbrella system. A particular attention must be paid when hydraulic conditions are not easy to control.

\section{CONCLUSION}

A complete calculation procedure for the analysis of pre-reinforcement interventions using longitudinal bolts and/or umbrella support systems at the excavation face in shallow tunnels has been illustrated in this study. This unified procedure can also take into account of free length, of the groundwater and of the pre-support techniques. The developed calculation approach is based on the limit equilibrium method applied to the ground core ahead of the excavation face; it is able to evaluate, in detail, the interaction between each reinforcement element and the surrounding ground and it permits the maximum static contribution that each reinforcement and pre-support element is able to give to the stability of the face to be determined.

The consideration of the contribution of the prereinforcement, the free length, the groundwater and the pre-support techniques in the limit equilibrium method leads to the definition of the safety factor at the face in presence of the reinforcement system.

The calculation procedure has been applied to a real Italian tunnel case and the influence of several important parameters during the excavation has been studied. The results show that the longitudinal fibreglass dowels permits to stabilize the tunnel face and prevent it from collapse. The free length if not higher than a third of the tunnel diameter have a slight influence on the tunnel safety factor. The pipe umbrella pre-support support system permits to increase this unspanned length avoiding the reduction of the face safety factor. The major influencing element in this type of analysis is the groundwater. To establish a correct design, the hydraulic conditions must therefore be controlled also using longitudinal drainage holes at the face.

\section{REFERENCES}

Benedetto, W., D. Scataglini and A. Selleri, 1991. Evoluzione dei sostegni in galleria dalle armature classiche alla vetroresina. Il Consolidamento del suolo e delle rocce nelle realizzazioni in sotterraneo. Milano (Italy), 18-20 Marzo 1991. Soc. Italiana Gallerie, 1: 73-97.

Dias, D., R. Kastner and P. Dubois, 1997. Tunnel face reinforcement by bolting: Strain approach using 3d analysis. Proceedings of one Day Seminar and International Conference, Oct. 27-29, BASEL, Switzerland, pp: 163-74. http://trid.trb.org/view.aspx?id=477263

Dias, D., R. Kastner and P. Dubois, 1998. Effects of prelining on the tunnel design. Proceedings of the International Conference on Underground in Modern Infrastructure Stockholm, (UMIS' 98), Sweden.

Do, N.A., D. Dias, P. Oreste and I. Djeran-Maigre, 2013. 2D numerical investigation of segmental tunnel lining behavior. Tunnell. Underground Space Technol., 37: 115-127. DOI: 10.1016/j.tust.2013.03.008

Hallak, R.A., J. Garnier and E. Leca, 1999. Experimental study of the stability of a tunnel face reinforced by bolts. Proceedings of the Geotechnical Aspect of Underground Construction in Soft Ground: Balkema, Rotterdam, (BR '99), pp: 1-5.

Kamata, H. and H. Mashimo, 2003. Centrifuge model test of tunnel face reinforcement by bolting. Tunnelling Underground Space Technol., 18: 205212. DOI: $10.1016 / \mathrm{S} 0886-7798(03) 00029-4$

Lunardi, P., 2008. Design and Construction of Tunnels: Analysis of Controlled Deformations in Rock and Soils. 1st Edn., Springer, Berlin, ISBN-10: 3540738754, pp: 594.

Oreste, P. and D. Dias, 2012. Stabilisation of the excavation face in shallow tunnels using fibreglass dowels. Rock Mech. Rock Eng., 45: 499-517. DOI: 10.1007/s00603-012-0234-1

Oreste, P., 2003. A Procedure for determining the reaction curve of shotcrete lining considering transient conditions. Rock Mech. Rock Eng., 36: 209-236.

Oreste, P., 2009. Face stabilization of shallow tunnels using fibreglass dowels. Proc. Instit. Civil Eng.Geotechnical Eng., 162: 95-109. DOI: 10.1680/geng.2009.162.2.95

Oreste, P., 2013. Face stabilization of deep tunnels using longitudinal fibreglass dowels. Int. J. Rock Mech. Min. Sci., 58: 127-140. DOI: 10.1016/j.ijrmms.2012.07.011 